\title{
QUALITY OF BASIC CHILD IMMUNIZATION PROGRAM ACCORDING TO MINIMUM SERVICE STANDARD AT COMMUNITY HEALTH CENTER
}

\author{
Chamelia Anggraeni Probo Sitihajar'), Dumilah Ayuningtyas²) \\ ${ }^{1)}$ Quality of Health Services, Faculty of Public Health, Universitas Indonesia \\ ${ }^{2)}$ Department of Health Administration Policy, Faculty of Public Health, \\ Universitas Indonesia
}

\begin{abstract}
Background: Universal immunization of children against six preventable diseases (tuberculosis, diphtheria, pertussis, tetanus, polio, and measles) is vital to reduce childhood mortality and morbidity across the world. Although immunization coverage in Indonesia is increasing year by year, it still falls short of the WHO and UNICEF's goals as stated in their Global Immunization Vision and Strategy: to reach $90 \%$ of children under the age of one with routine immunization nationwide, and at least $80 \%$ in every district in the country by the year 2020. Almost half (46.64\%) of children in Indonesia did not receive complete immunization in 2012. This study aimed to examine the quality of basic child immunization program according to minimum service standard at Community Health Center.

Subjects and Method: This was a qualitative study with Rapid Assesment Procedure approach in July 2019. Total of 14 informants were selected for this study including: chief of individual health unit, program director, and 12 program managers. The study theme was completeness and quality of basic child immunization program according to minimum services standard. The data were collected by in-depth interview, focus group discussion, and document review. The data were analyzed by content analysis.

Results: Input and process of child immunization program were not in accordance with the minimun service standard set by the Ministry of Health. The number of immunization workers was lacking, training was uneven, work rotation was too fast, infant data was incompatible, health workers neglected to wash their hands, and staff knowledge about vaccine-associated adverse events and anaphylatic shock was uneven. The child immunization target output has been achieved.

Conclusion: Community health center have not maximally performed complete basic child immunization service in accordance with the Minimum Service Standard set by the Indonesian Ministry of Health in terms of input and process. The child immunization target output has been achieved.
\end{abstract}

Keywords: quality, complete immunization, minimum service standard

\section{Correspondence:}

Chamelia Anggraeni P S. Quality of Health Services, Faculty of Public Health, Universitas Indonesia. Email: chameliaaps12@gmail.com. Mobile: 081284200488

\begin{tabular}{l} 
BACKGROUND \\
\hline According to the World Health Organiza- \\
tion (WHO), The Children Under-Five Mor- \\
tality Rate globally decreased from 91 to 43 \\
per 1000 live births in 2015; it has decree- \\
sed by 53\% since 1990 (WHO, 2015). Based
\end{tabular}

on the data from the Ministry of Health in 2015, the Under-Five Mortality Rate in Indonesia was 26 per 1,000 live births, which means that it has met the 2015 Millennium Development Goals (MDGs) target of 32 per 1,00o live births. However, Indo- 
nesia must continue to process the outcomes of the Sustainable Development Goals (SDGs) in 2030. One of the outcomes is to end the preventable infant and children under five deaths. All countries are trying to reduce the Neonatal Mortality Rate by at least 12 per 1,000 live births and UnderFive Mortality Rate by 25 per 1,000 live births (Ministry of Health, 2015).

One of the government's strategies and efforts to support efforts in reducing the Under-Five Mortality Rate is increasing immunization coverage, where the $87 \%$ of deaths occurred due to Preventable Diseases by Immunization. This can be conducted through a complete basic immunization program (Ministry of Health, 2015).

This is in line with Health Law No. $36 / 2009$ that every child has the right to obatin basic immunization in accordance with the provisions to prevent the occurrence of diseases that can be avoided through immunization. In addition, the government is obliged to provide complete immunization to every infant and child. The implementation of immunization is also stated in the Minister of Health Regulation No. 12 of 2017 which was promulgated on 11 April 2017 replacing the Minister of Health Regulation No. 42 of 2013 which states that immunization is an effort to actively raise or increase one's immunity against a certain disease, so that the child will not sick or only have mild illness if one day is transmitte to the disease (Ministry of Health Decree, 2004).

One of the preventive efforts to prevent disease is through the provision of immunity. It must be carried out continuously, thoroughly, and carried out according to standards, thus giving health protection and breaking the chain of transmission. Immunization is one of the health interventions that is proven to be the most costeffective because it can prevent and reduce the incidence of morbidity, disability, and death due to Preventable Diseases by Immunization including tuberculosis, diphtheria, tetanus, hepatitis B, pertussis, measles, rubella, polio, inflammation of the membranes brain, and inflammation of the lungs that are estimated to be 2 to 3 million deaths annually (Ministry of Health Decree, 2004).

Based on case reports of the Preventable Diseases by Immunization in 2017 gradually improved with the target of $100 \%$ complete immunization, namely:

1. The cases of Tetanus Neonatrum in 2016 were 33 cases, while in 2017 it decreased to 25 cases from 7 provinces with the number of deaths by 14 cases.

2. There were 15,104 suspected cases of measles which occurred in almost all provinces of Indonesia, the number was higher than the number of cases in 2016 by 12,681 cases. The highest number of cases of measles suspect (more than 1,00o cases) was from East Java Province $(3,547$ cases), DI Yogyakarta Province (2,186 cases), DKI Jakarta province (1,196 cases), and West Java (1,067 cases). The measles Incidence Rate (IR) in 2017 was 5.77 per 100,000 population. It increased compared to 2016 which was 5.0 per 100,000 population.

3. The number of diphtheria cases in 2017 was 954 cases with 44 cases of death cases, so that the CFR of diphtheria in Indonesia in 2017 was $4.61 \%$.

4. For polio cases, Indonesia has succeeded in obtaining polio-free certification (Ministry of Health RI, 2018).

Health Minimum Services Standard, abbreviated as HMSS is a reference for Regency/City Governments in providing health services that are entitled to be obtained by every citizen at a minimum. Due to the condition of the ability of Regional Government resources throughout Indone- 
sia are not the same in carrying out the six functions, the implementation of these functions is regulated by a Minimum Service Standard to ensure the availability of these services for all citizens. The MSS has at least two functions, i.e.

1. Facilitating the local government to conduct appropriate public services for the community and

2. As an instrument for the community in controlling the performance of the government in the field of public health services. These factors make all elements combined to improve and work together towards the achievement of MSS targets, including the fulfillment of health human resources, especially at the level of Community health center. It is in line with Minister of Health Regulation No. 75 of 2014 regarding Community Health Centers. Community health center as a first-level health service facility will be the frontline unit in reaching MSS targets.

Minister of Health Regulation No. 75 (2014) regarding Community health center states that Community health center is a health service facility that carry out public health efforts and first-level Individual Health Efforts. It prioritizes health promotion and disease prevention program in order to achieve the highest degree of public health in the working area. Community health center is expected to be able to implement health policies to achieve the goals of health development in their working area in order to support the realization of Healthy Districts. It is expected that 6,000 Community health centers in 2019 can provide services according to the standard. Based on the result of filling in the self-assessment instruments conducted by the Community health center in 2017 , there were 3,225 Community health centers that had provided services according to the stan- dard, from 3,392 Community health centers that had reported it to the center.

Universal Child Immunization (UCI) of village/village office is a description of a village/village office where $\geq 80 \%$ of the total number of infants (o-11 months) in the village/village office has received complete basic immunization. In 2017, the coverage of UCI villages in Indonesia was $80.34 \%$. There were three provinces with the highest achievements: Special Region of Yogyakarta (100\%), Special Capital Region of Jakarta (100\%), and Central Java (99.95\%). Meanwhile, the provinces with the lowest achievements were Papua (21.43\%), North Kalimantan (51.98\%) and Maluku (59.95\%) (Indonesian Pediatric Society, 2018).

The Community health center in $\mathrm{X}$ sub-district area was one of the main health facilities in South Jakarta that has received plenary accreditation and achieved 100\% target in the indicators of labor achievement in health facilities in 2018. This Community health center has 11 Immunization Poly in 10 Community health centers in the office village and 1 Community health center in the distric. It met the UCI criteria with the $97 \%$ achievement in the total target of 6,387 children under five in 2018 . The researchers and the Team also had previously conducted a study on the analysis of MSS in neonatal at X Community health center due to 2 cases of neonatal deaths. It occurred due to unpreparedness of neonatal services that were not in line with the standards. In addition, the Community health center was very useful, so that the researchers continued study in other MSS fields. Based on the explanation above, this study aimed to analyze the quality of the implementation of health services in children under five on the complete basic immunization programs at X Community health center through an analysis of the readiness of inputs and processes in achie- 
ving under-five health services in accordance with standards set by the Ministry of Health.

\section{SUBJECTS AND METHOD \\ 1. Design of the Study}

This was a qualitative study with rapid assessment design. This study was conducted at Community health center at X Subdistrict, South Jakarta on July 25-31, 2019. This study used qualitative data obtained through in-depth interviews, focus group discussions, and non-participatory observation using in-depth interviews, FGDs, and observation guides. The sources of data involved were the Chairperson of the Individual Health Efforts, the person in charge of the immunization program, and 12 implementers of the X sub-district immunization program that spread across 11 villages; and observation on services, supporting facilities, and documents related to complete basic immunization at X Community health center. The data were processed by making interview transcripts, coding and summarizing data in the form of a matrix. The data were analyzed by reviewing all information obtained, grouping them based on questions and variables, and identifying answers that often appeared.

\section{RESULTS}

1. Input

a. The implementer for the immunization according to the qualification was divided into midwives and nurses, all of them had Registration Certificate.

b. There were differences in answers from management and implementer, the management felt that the number of people was sufficient, while the implementer complained about the lack of people, especially in the immunization activities carried out outside the building, also the heavy workload due to the 3-5 program handled by one staff besides the program complete basic immunization.

c. The training has not been evenly conducted to all staff due to the rapid rotation of work (less than three years)

d. Vaccines were always available at the sub-district pharmacy, but the minimum stock taking was not in line with the reference which was $10 \%$ of the total needs.

e. The Complete Basic Immunization (CBI) program guidelines at X Community health center were complete and up to date, followed by the renewal of the SOP.

f. The supporting tools for the complete CBI program were available, could be used, and always maintained

\section{Process}

a. Planning conducted by the parties of $\mathrm{X}$ Community health center was perfect, following the rules of the "bottom-up mechanism", where each program holder would be given a planning form for one year, which discussion would be carried out together with the management

b. The parties of the Community health center and staff complained about the discrepancy between the number of children under five from the data at the office and the actual number of children under five, the number of the discrepancy reached 2-3 times more than the real number of children under five in the region. It occurred due to the large number of evictions, the number of offices, and the high mobility of the population.

c. The $100 \%$ target was impossible to achieved due to the gap in the num- 
ber of children under five, responded by collaborating with hospitals, clinics, and Central Bureau of Statistics located in the $\mathrm{X}$ Community health center sub-district area by giving free vaccines that were replaced by reporting data on the names of children under five who were given the immunization, even though the children under five did not live in $\mathrm{X}$ sub-district, the data would still be collected because the children under five received services in $\mathrm{X}$ sub-district.

d. The data of children under five for reporting was divided into two, namely projection data and real data. Projection data was the total number of children under five immunizing in the $\mathrm{X}$ sub-district area, while the real data was the real number of children under five who lived in X sub-district and have been immunized.

e. Reporting was conducted with a children under five cohort, an immunization website from the department, and was backed up with an ENA system developed by the parties of the Community health center to facilitate reporting. However, the problem of the system was difficult to track if we want to see the past reports. Therefore, the staff who conducted immunization designed manual Vaccination records for easy tracking.

f. The infrastructure of X Community heakth center has been perfect, especially in maintaining vaccine quality, even in its distribution the parties of the Community health center would refuse if other parties who took the vaccine did not comply with the stated storage standards. g. Even though the placement and assignment of responsibilities was not compromised, but directly from superiors, the implementers continued to carry out their obligations.

h. Immunization service was not in line with the standard, it could be seen from the officers who did not wash their hands according to the SOP that was posted. In addition, the officers only washed their hands at the beginning of the service.

i. Lack of knowledge of immunization officers could be seen. Although the knowledge of complete basic immunization was good, but not all officers understood the symptoms and management of adverse events following immunization (AEFI) and anaphylatic shock. In addition, this knowledge was very important for officers to know.

j. For tracking incomplete targets, immunization officers carried out cross-sectoral collaboration such as with cadres, Neighborbood Association, Citizens Associations, and village office to help sweep children under five and complete their immunizations in their regions.

k. The obstacle of the complete basic immunization program that occurred at X Community health center was the difficulty in monitoring the status of immunization in children under five with middle to upper economic level. In addition, there were still parents and schools that were Anti-Vaccine.

1. Monitoring and evaluation has been carried out regularly, both reporting that was carried out every morning by the person in charge, and a regular monthly event that would be 
attended by all relevant program officers.

\section{Output}

Eventhough the X Community health center has joined the Universal Child Immunization (UCI) because it always met the immunization target, even in 2018 it was recorded $97 \%$, but the implementation of MSS in complete basic immunization is still not in line with the standards set by the Indonesian Ministry of Health. Some of the shortcomings were the insufficient number of immunization officers, unbalanced amount of training, rapid job rotation, mismatched data for children under five to reach targets, negligence of officers in washing hands, and uneven officers' knowledge of AEFI and anaphylatic shock.

\section{DISCUSSION}

This study recorded the suitability of inputs and processes for outputs of the service standards set by the Ministry of Health of the Republic of Indonesia. The shortcomings were:

\section{a. The Discrepancy Type and Number of Officers}

As stated in Minister of Health Regulation No. 43 regarding Minimum Service Standards for children under five, the human resources needed in the implementation of services are midwives, nurses, nutritionists, doctors, and pediatricians. In the immunization program at $\mathrm{X}$ Community health center, the types of personnel involved were appropriate, namely midwives and nurses. Meanwhile, the nutritionists were in the other programs which also included in the children under five services. However, there were no doctors directly involved with children under five health services. If it is needed, the doctor who was on duty will help to take over it. The unavailability of pediatricians at X Community health center made a mismatch between the types of personnel listed on the MSS and those available at the Community health center.

Based on the Minister of Health Regulation No.12 of 2017 Article 24 paragraph 3, all management personnel must meet the qualifications and competencies obtained from education and training as evidenced by the competency certificate. In this case, all midwives and nurses of the immunization program had Registration Certificate with the active validity period. However, there was a discrepancy in Article 24 paragraph 2 which states that the management staff consists of one program manager and one logistics manager. This was not in line with the availability of personnel at the Community health center, where each Community health center only had $1 \mathrm{immu-}$ nization officer who became an implementer as well as logistic staff. The discrepancy was strengthened by the result of the FGD which stated that one immunization officer was responsible for more than 3 programs. In addition, one officer was also responsible for the implementation of the immunization outside and inside the building.

\section{b. The Rapid Job Rotation}

The management staff who had received training should not be transferred at least 3 (three) years after training (Decree of the Minister of Health No.4/2017). This was also complained by the person in charge of the immunization program during an indepth interview. The lack of health workers affected the rapid job rotation. Therefore, the person in charge of the program had to train and educate new staff. It was strengthened by the FGD statement which stated that rotation could be carried out even in less than 2 years. It was also the main cause of the uneven education and training of the immunization workers. 


\section{c. The Uneven Training}

Training is an effort to improve the knowledge, attitude, and skills of officers/management staff of immunization in order to improve the performance and the quality of officers. The training is expected to be accredited and have a certificate. The types of training are the concept of training (pre service training, in service training, apprenticeship training, formal training, on the job training, advanced training) and training development by using an accredited Competency-Based Training (CBT) approach (Decree of the Minister of Health No.4/2017 ). This is not entirely in line with the training carried out by the Community health center. The education and training from the Health Office is only attended by the person in charge of the program. However, it will be directly socialized by other officers. Based on the results of the FGD's answers regarding the immunization knowledge, the officers did not master some material, such as AEFI and anaphylatic shock. The result of the observation of the management, the officer still has not conducted the procedure for giving immunizations in accordance with the SOP that the Community health center has.

\section{d. The Low Knowledge of Officers about the Adverse Events Follow- ing Immunization (AEFI)}

The main purpose of AEFI monitoring is to detect early, respond to AEFI quickly and appropriately, reduce the negative effect of immunization on individual health and on immunization. This is an indicator of the quality of the program. The most important part of AEFI monitoring is to provide complete AEFI information. Therefore, it can be quickly assessed and analyzed to identify and respond to a problem (Ministry of Health Regulation No.12/2017).
Based on the result of this study, all officers knew the reporting flow of AEFI However, nobody was able to mention the signs and symptoms of AEFI completely. The latest AEFI form has been well socialized, the anaphylactic kit was complete, sealed, and ready to use. However, only 3 out of 12 officers who knew the symptoms and the treatment of anaphylic shock. This indicated that the officers' knowledge of AEFI was uneven. Before carrying out immunization services, health workers must also provide an explanation of Immunization including the type of vaccine, the benefits, the consequences if the children are not immunized, the possibility of an AEFI, and the efforts that must be carried out, as well as the next immunization schedule. If the officer does not have enough knowledge, the information provided to parents/guardians of children under five will be ineffective.

Robert T. Chen has estimated the course of the Immunization program as being linked to maturation of community trust and its effect on a disease. However,the Immunization program will lead to a process of maturation of community perceptions regarding vaccine side effects that may arise. Therefore, the disease will reappear in the form of outbreak. Before it happens, the officers must quickly deal with AEFI (Chen, 2015).

\section{e. The Negligence of the Officers in Washing Hands}

WHO has established five opportunities for hand hygiene: before touching the patient, before conducting aseptic intervention, after carrying out the procedure or exposure to patient's body fluids, after touching the patient, and after contacting the patient's environment (Ministry of Health RI, 2018).

The importance of hand washing is also supported in the training module of the 
Immunization officer unit of Indonesian Pediatric Society. The overall guidelines for managing the types of immunization begin with hand washing (IDAI, 2011).

Based on the result of the management observation, the officer only washed their hands once. It was carried out before injecting the children under five who came first. In addition, the hand washing was also not in line with the SOP of hand washing listed on the washbowl at $\mathrm{X} \mathrm{Commu-}$ nity health center.

\section{f. The Discrepancy Between the Data of Children Under Five and the Target Achievement}

Determining the number of targets is an important activity. It becomes the basis of implementation planning, monitoring, and program evaluation. The target number is determined by the Central Bureau of Statistics every 10 years and the Census and the Inter-Census Population Survey (SUPAS). The smallest unit is the village. This rate is the basis for each administrative region to make projections. Because the smallest unit is a province, the accuracy of the projection result is only limited to the province. It often creates a gap between the projected number and the actual population. The situation analysis used is a map of the area with the number of population/target, regional data, existing immunization service units, morbidity and mortality data, the result of the analysis on monitoring local area, and evaluation (Decree of the Minister of Health RI, No.1056/2004).

The discrepancy of the projected data was also complained by the Head of Individual Health Efforts at the X Community health center sub-district area and the person in charge of the program in an in-depth interview. It occurred due to many residential areas were evicted into offices, high migration that were not followed by file transfers, and the difficulty to reach the upper middle class community. The number of targets which was 3 times more than the number of children under five living in the area made the target difficult to achieve. The officers conducted sweeping with cross-sectoral assistance such as cadres, Neighborbood Association, and people in the village. Therefore, the data collection for children under five living in $\mathrm{X}$ sub-district was more optimal. In reaching the $95 \%$ coverage target, the parties from Community health center collaborated with hospitals, clinics, and private midwives located in the sub-district area in order to reach the target. Community heatlh center provided free vaccines which must be exchanged with the immunization data. As a result, all of the children under five who were immunized at the health service unit in the X sub-district area could be included in the achievement target, eventhough they did not live in the $\mathrm{X}$ sub-District area. It was what makes the achievement result of the X Community health center always reached the target.

\section{REFERENCES}

Chen RT (2015). Safety of vaccines. In : Plotkin SA, Mortimer WA, editor. Vaccines. Edisi Ketiga. Philadelphia, WB Saunders. Tokyo

Ikatan Dokter Anak Indonesia (2011). Buku imunisasi di Indonesia (Immunization books in Indonesia). Jakarta: Satgas Imunisasi IDAI

Ikatan Dokter Anak Indonesia (2018). Pedoman Imunisasi di Indonesia 5 ed (Indonesian immunization guidelines 5 ed). Jakarta: Badan Penerbit Ikatan Dokter Anak Indonesia.

Ikatan Dokter Anak Indonesia (2018). Pelatihan Imunisasi Dasar. Kejadian Ikutan Pasca Imunisasi (Basic immunization training. Post-immunization 
events). Jakarta: Satgas Imunisasi IDAI

Ministry of Health (2015). Data dasar Puskesmas (Basic data of public health center). Ministry of Health.

Ministry of Health (2017). Imunisasi measles rubella lindungi anak kita.

Ministry of Health (2015). Kesehatan dalam kerangka sustainable development goals (SDGs). Jakarta: WHO.

Ministry of Health (2018), Pelayanan kesehatan neonatal esensial, pedoman teknis pelayanan kesehatan tingkat pertama tahun 2018 (Essential neonatal health services, the first level of health Care Technical guideline year 2018). Jakarta.

Ministry of Health (2017). Sekretariat jenderal profil kesehatan Indonesia tahun 2017 (Secretariat general of Indonesian health profile 2017). Jakarta

Decree of the Minister of Health RI No. 4 (2017). Perubahan kedua atas Peraturan Menteri Kesehatan Nomor 52 tahun 2016 tentang standard tarif pelayanan kesehatan dalam penyelenggaraan program jaminan kesehatan (Second Amendment to regulation of the Minister of Health No. 52, 2016 on standard health care tariff in the implementation of health care insurance Program).

Decree of the Minister of Health RI No. 1056 (2004). Lokus program Indonesia sehat dengan pendektan keluarga (A healthy Indonesian program locus with a family).

Decree of the Minister of Health RI No. 1059 (2004). Pedoman penyelenggaraan imunisasi (Immunization implementation guidelines).

Decree of the Minister of Health RI No. 12 (2017). Penyelenggaraan imunisasi (Immunization maintenance)

Undang-Undang Republik Indonesia Nomor 36 Tahun 2009 Tentang Keseha$\tan$ (Law of the Republic of Indonesia number 36 year 2009 about health) 